\title{
Constipation and a Low-Fiber Diet are Not Associated with Diverticulosis
}

\author{
Anne F. Peery, MD1', Robert S. Sandler, MD1, Dennis J. Ahnen, MD², Joseph A. Galanko, \\ $\mathrm{PhD}^{1}$, Adrian N. Holm, DO ${ }^{3}$, Aasma Shaukat, MD ${ }^{4}$, Leila A. Mott, $\mathrm{MS}^{5}$, Elizabeth L. Barry, \\ $\mathbf{P h D}^{5}$, David A. Fried, $\mathbf{B S}^{5}$, and John A. Baron, $\mathbf{M D}^{1,5}$ \\ ${ }^{1}$ University of North Carolina School of Medicine, Chapel Hill, NC \\ ${ }^{2}$ Denver VA Medical Center and University of Colorado Anschutz Medical Campus, Denver, CO \\ 3University of lowa Hospitals and Clinic, lowa City, IA \\ ${ }^{4}$ Minneapolis Veteran Affairs Medical Center, Minneapolis, MN \\ ${ }^{5}$ Geisel School of Medicine at Dartmouth, Hanover, NH
}

\begin{abstract}
Background \& Aims-Asymptomatic diverticulosis is commonly attributed to constipation secondary to a low-fiber diet, although evidence for this mechanism is limited. We examined the associations between constipation and low dietary fiber intake with risk of asymptomatic diverticulosis.
\end{abstract}

\begin{abstract}
Methods-We performed a cross sectional study, analyzing data from 539 individuals with diverticulosis and 1569 without (controls). Participants underwent colonoscopy and assessment of diet, physical activity and bowel habits. Our analysis was limited our analysis to participants with no knowledge of their diverticular disease, to reduce the risk of biased responses.
\end{abstract}

Results-Constipation was not associated with an increased risk of diverticulosis. Participants with less frequent bowel movements (BM: $<7 / \mathrm{wk}$ ) had reduced odds of diverticulosis compared to those with regular (7/wk) BM (odds ratio [OR] 0.56, 95\% confidence interval [CI], 0.40-0.80). Those reporting hard stools also had a reduced odds (OR, 0.75; 95\% CI, 0.55-1.02). There was no association between diverticulosis and straining (OR, 0.85 ; 95\% CI, 0.59-1.22) or incomplete BM (OR, $0.85 ; 95 \% \mathrm{CI}, 0.61-1.20)$. We found no association between dietary fiber intake and

\footnotetext{
(C) 2013 The American Gastroenterological Association. Published by Elsevier Inc. All rights reserved.

Corresponding Author, Anne F. Peery, MD MSCR, Fellow, Division of Gastroenterology and Hepatology, University of North Carolina School of Medicine, Bioinformatics Building, CB \# 7080, 130 Mason Farm Road, Chapel Hill, NC 27599-7555, Phone: (919) 593-5278, Fax: (919) 843-2793, apeery@unch.unc.edu.

Publisher's Disclaimer: This is a PDF file of an unedited manuscript that has been accepted for publication. As a service to our customers we are providing this early version of the manuscript. The manuscript will undergo copyediting, typesetting, and review of the resulting proof before it is published in its final citable form. Please note that during the production process errors may be discovered which could affect the content, and all legal disclaimers that apply to the journal pertain.

Disclosures: None

Writing Assistance: None

Author Contributions: Anne F. Peery - literature search, study design, data analysis, data interpretation, manuscript preparation; Robert S. Sandler - literature search, study design, data analysis, data interpretation, manuscript preparation; Dennis J. Ahnen - data interpretation, manuscript preparation; Joseph A. Galanko- data analysis, data interpretation, manuscript preparation; Adrian N. Holm - data interpretation, manuscript preparation; Aasma Shaukat - data interpretation, manuscript preparation; Leila A. Mott - data analysis, data interpretation, manuscript preparation; Elizabeth L. Barry- data analysis, data interpretation, manuscript preparation; David A. Fried - data collection, data interpretation, manuscript preparation; John A. Baron - literature search, study design, data analysis, data interpretation, manuscript preparation
} 
diverticulosis (OR, 0.96 ; 95\% CI, 0.71-1.30) in comparing the highest quartile to the lowest (mean intake 25 versus $8 \mathrm{~g} /$ day).

Conclusions-In our cross-sectional, colonoscopy-based study, neither constipation nor a lowfiber diet was associated with an increased risk of diverticulosis.

\section{Keywords}

diverticular disease; risk factors; database analysis

In the United States, about two thirds of adults over the age of 85 have asymptomatic diverticula in the descending or sigmoid colon. ${ }^{1}$ Diverticulosis can become complicated by inflammation, hemorrhage or perforation, so called diverticular disease. In 2009, Americans spent more than 1.3 million days in the hospital with a diagnosis of diverticular disease. ${ }^{2}$ In that same year, diverticular disease was responsible for 283,355 hospitalizations, 2,682,168 ambulatory care visits and 1,948 in-hospital deaths in the United States. ${ }^{2}$ Inpatient costs totaled 2.7 billion dollars for 2009 alone. $^{2}$

Despite the burden of diverticular disease, its pathophysiology remains poorly understood. Several risk factors for symptomatic diverticular disease have been identified including obesity, physical inactivity and a low fiber diet. ${ }^{3-9}$ However, risk factors for diverticula development are likely different from those for inflammation, bleeding or perforation. Proponents of the long-standing fiber hypothesis for diverticula formation argue that the colon must generate excessively high pressures to move small caliber, hard stools. ${ }^{10}$ Purportedly, these high pressures lead to mucosal herniation and creation of pseudo diverticula in the descending or sigmoid colon. ${ }^{10}$ Consequently, constipation from a low fiber diet is commonly cited as the etiology of descending or sigmoid colon diverticulosis. Despite limited research or evidence, this hypothesis has been widely accepted. ${ }^{11,12}$ Few alternative risk factors for asymptomatic diverticulosis have been studied. ${ }^{3,12,13}$

To explore risk factors associated with diverticulosis, we analyzed comprehensive data from a colonoscopy-based study that collected detailed information on diet, physical activity and body mass index. We considered multiple risk factors for diverticulosis including diet (low fiber, high fat, high red meat), frequency of bowel movements, symptoms of constipation, tobacco use, alcohol use, non-aspirin NSAID use, aspirin use, physical activity, obesity, and race. We limited our analysis to participants who denied a history of diverticulosis or diverticulitis because participants with a history of diverticulosis or diverticular disease may have increased their fiber intake or undertaken other lifestyle changes in response to their diagnoses.

\section{METHODS}

\section{Study Population}

We analyzed data on 2,813 enrollees from the Vitamin D and Calcium Polyp Prevention study (Clinical Trials.gov ID NCT00153816). We excluded participants with a history of self-reported diverticulosis or diverticulitis. Cases were participants found to have colonic diverticula noted in the colonoscopy reports at study entry. Controls were participants without colonic diverticula. A research assistant who was trained in data abstraction and blinded to the exposure variables abstracted reports of colonic diverticula from the participant's baseline colonoscopy report.

The Vitamin D and Calcium Polyp Prevention study is a double-blind, placebo-controlled trial of vitamin $\mathrm{D}$ and/or calcium supplementation for the prevention of colonic adenomas. Participants were recruited from eleven study centers in North America between July 2004 - 
July 2008. Eligible participants had at least one histologically verified colonic adenoma removed in the four months prior to study entry and no remaining polyps in the bowel after complete colonoscopic examination. Eligible participants were between the ages of 45 and 75 with satisfactory preparation for colonoscopy and a complete exam to the cecum.

The parent study excluded patients with a history of previous colon resection or a diagnosis of familial colorectal cancer syndrome, inflammatory bowel disease, chronic intestinal malabsorption, invasive colon cancer, or severe lung, heart, kidney or liver disease.

The parent study was approved by the Institutional Review Boards of each study center. Secondary data analysis at the University of North Carolina was limited to data with no direct patient identifiers and was exempt from Institutional Review Board review. The STROBE guidelines for reporting descriptive observational studies were followed. ${ }^{14}$

\section{Assessment of Variables}

Within 120 days after the colonoscopy, each participant had an intake visit for the parent study in which information was collected on demographics, diet, bowel habits, physical activity, smoking history, alcohol use, prescription and over the counter medication use, and co-morbidities. Race was self-reported. Height and weight were either measured (70\% and $72.3 \%$, respectively) or collected by self-report ( $29.6 \%$ and $24 \%$, respectively) at this visit.

A baseline history of diverticulosis or diverticulitis was assessed as one of a series of questions of the form, "Has a doctor ever told you that you have any of the following?" "Diverticulitis/Diverticulosis?" was one of the disorders listed. Responses were captured as either no, yes, don't know or refused. Dietary information was collected using the Block Brief 2000 Food Frequency Questionnaire, a food frequency questionnaire with 60 food items. ${ }^{15}$ Participants were asked to report their usual diet during the one year prior to their colonoscopy to avoid seasonal variation in diet.

Physical activity was measured using the validated International Physical Activity Questionnaire. ${ }^{16}$ All physical activity was classified into metabolic equivalents. Sedentary behavior was assessed with the question, "During the last 7 days, how much time did you usually spend sitting on a week day?"

Aspirin use was assessed with the question, "In the last four months, have you taken any medicines containing aspirin?" If yes, "How often, on average, on a weekly basis, were you taking it?" Regular aspirin use was defined as one or more days of aspirin use per week. NSAID use was assessed with the question, "In the last four months, have you taken any other medications for aches, fevers, pain, swelling or inflammation?" If yes, "How often, on average, on a weekly basis, were you taking it?" Regular NSAID use was defined as one or more days of NSAID use per week. Smoking was assessed with the question "Have you smoked at least 100 cigarettes in your entire life?" Those who were categorized as "never" smoked less then 100 cigarettes in their entire life. Alcohol use was assessed with number of alcoholic drinks per day over the last year.

Abdominal pain was assessed as one response to the question, "In the past year, have you experienced any of the following?" "Pain in your abdomen?" was one of the listed symptoms. The response was captured as none, some, severe, don't know or refused.

Bowel habits over the past year were assessed with the following questions. "What percent of the time did you have to strain during a bowel movement?" "What percent of the time did you have a feeling that you did not empty your bowels completely or that you were not finished?" and "What percent of the time did you have hard or lumpy stools?" These 
responses were captured as either less than $25 \%$ of the time, $25 \%$ or more, don't know or refused. Lastly, "How many bowel movements did you have?" The response was captured as either number per day or number per week.

Prescription and over-the-counter laxative use was captured. Data regarding supplemental fiber use was also obtained.

\section{Statistical Analysis}

Means and standard deviations were reported for continuous variables. Medians were reported for skewed distributions of continuous variables. Proportions were reported for categorical data. Dietary data, alcohol use, physical activity and sedentary behavior were converted into categories (quartiles) for analyses. Categorical indictor variables were created to summarize bowel movement patterns. The four categories were: 1) $<7$ bowel movements per week; 2) 7 bowel movements per week; 3) 8-14 bowel movements per week; and 4)>15 bowel movements per week. The $10 \%$ change-in-estimate approach was used to assess the following variables for confounding: age, sex, race, education, BMI, NSAID use, ASA use, tobacco use, alcohol use, physical activity, abdominal pain, dietary fiber intake and laxative use. Multivariate analyses were performed using logistic regression to estimate odds ratios and $95 \%$ confidence intervals while adjusting for age and sex. Fiber, dietary fat and red meat intake were adjusted for total caloric intake using regression residuals. ${ }^{17}$ All tests of significance were two-tailed and p-values $<0.05$ were considered significant. The analysis was performed using SAS 9.2 (SAS, Cary, North Carolina).

\section{RESULTS}

Our analysis began with 2,813 enrolled study participants. We excluded 698 subjects who reported a history of diverticulosis or diverticulitis and 7 participants with no data on diverticular history, leaving 539 who met our case definition of having colonic diverticula and 1,569 controls without diverticula. Most cases (88\%) had descending or sigmoid colon diverticula. The rest had pancolonic diverticula $(6 \%)$, cecal or ascending colon diverticula $(2 \%)$, or diverticula in an undocumented location (4\%). Participants with diverticulosis were older, more likely to be male and Caucasian, had a higher mean body-mass index, and used tobacco, aspirin and alcohol more frequently than controls (Table 1).

Diverticulosis cases reported more frequent bowel movements compared with controls (9.6 versus 8.7 bowel movements per week, $\mathrm{p}=0.0003$ ) (Table 1 ). Infrequent bowel movements were not associated with an increased prevalence of diverticulosis. Instead, those having less frequent bowel movements $(<7)$ per week had a reduced odds compared to individuals with seven movements per week (OR 0.56, 95\% CI 0.40, 0.80). Compared to participants with seven bowel movements per week, those having 8-14 movements were more likely to have diverticulosis (OR 1.29, 95\% CI 1.02-1.64) as were those with 15 or greater bowel movements per week (OR 1.38, 95\% CI 0.90-2.12).

Cases reported frequent hard stools less frequently than controls ( $11 \%$ versus $15 \%, \mathrm{p}=0.02)$ (Table 1). Having hard or lumpy stools was associated with a reduced odds of diverticulosis (OR $0.75,95 \%$ CI $0.55,1.02$ ) (Table 2). There was no difference between cases and controls with regards to straining with a bowel movement $(9 \%$ versus $10 \%, \mathrm{p}=0.3)$ or incomplete bowel emptying during defecation ( $10 \%$ versus $11 \%, \mathrm{p}=0.2)$ (Table 1$)$. There was also no association between straining during bowel movements (OR $0.85,95 \%$ CI $0.59,1.22)$ or feeling of incomplete bowel movement (OR $0.85,95 \%$ CI $0.61,1.20)$ and diverticulosis (Table 2). 
We found no difference between the cases and the controls in mean dietary fiber intake (14.8 grams versus 15.3 grams per day, $\mathrm{p}=0.2$ ) and reported supplemental fiber intake (5\% versus $5 \%, \mathrm{p}=0.7$ ) (Table 1). Correspondingly, we found no association between dietary fiber intake (OR 0.96, 95\% CI 0.71-1.30) and diverticulosis when comparing the highest quartile of fiber intake (mean 25 grams/day) to the lowest (mean 8 grams/day) (Table 3). We also found no associations between dietary fiber intake by subtype (beans, grains, fruits and vegetables) and the presence of diverticulosis (Table 3).

We found no difference between the cases and the controls in reported laxative use (7\% versus $7 \%, \mathrm{p}=0.9)($ Table 1$)$

The same proportions of cases and controls reported abdominal pain (3\% versus $4 \%$, $\mathrm{p}=0.08$ ).

We also assessed alternative risk factors. Overweight participants (BMI $\geq 25 \mathrm{Kg} / \mathrm{m}^{2}$ ) had an increased odds of diverticulosis (OR 1.65, 95\% CI 1.27-2.15) compared to a normal BMI $\left(<25 \mathrm{Kg} / \mathrm{m}^{2}\right)$ (Table 4). Current smokers also had an increased odds (OR 1.42, 95\% CI 1.01-2.00) compared to never-smokers, as did former smokers (OR 1.24, 95\% CI 1.011.52) (Table 4). Non- Caucasian participants had a lower risk (OR 0.74, 95\% CI $0.55,1.00$ ) than Caucasians (Table 4). Dietary fat and red meat, NSAID and aspirin use, alcohol consumption, physical activity and sedentary behavior were not associated with diverticulosis (Table 3 and Table 4).

\section{DISCUSSION}

We examined the relationship between bowel habits, dietary fiber intake, and the risk of asymptomatic diverticulosis among participants enrolled in a large, multi-center, colonoscopy-based study. Contrary to current understanding, we found that less frequent bowel movements and hard or lumpy stools were associated with a decreased risk of diverticulosis. Classic symptoms of constipation, i.e. straining during bowel movements or a feeling of incomplete bowel movements were unassociated with diverticulosis. Also contrary to current understanding, we found no association between dietary fiber intake and diverticulosis.

Forty years ago, Dr. Neil Painter popularized the hypothesis that inadequate dietary fiber intake and constipation was the cause of sigmoid diverticulosis. ${ }^{18} \mathrm{He}$ believed that segments of contracting sigmoid colon generated high pressures in the setting of small caliber, hard stools. Further, he thought these high pressures lead to mucosal herniation and creation of pseudo diverticula. He associated small caliber, hard stool with a Western diet low in dietary fiber. Although the fiber hypothesis is conceptually attractive and widely accepted, it has not been rigorously examined. Colonic motility studies inconsistently demonstrate abnormally elevated colonic pressures in patients with diverticulosis. ${ }^{19-25}$ Most of these studies measured pressures in the rectum or rectosigmoid junction, and they were commonly underpowered and limited by selection bias. ${ }^{26}$ No study measured colonic motility prior to the development of diverticula.

Informal ecologic studies noting the rising prevalence of diverticulosis in industrialized countries compared with rarely diagnosed disease in rural Africa and Asia have also been used to support the fiber hypothesis. ${ }^{11}$ The reported differences in disease prevalence were attributed to differences in dietary fiber content. These ecologic observations did not actually determine the presence of diverticula in individuals, assess diet or account for potential confounding variables such as age and sex. 
Similarly, one study found that vegetarians had a reduced prevalence of diverticulosis compared to non-vegetarians and proposed that variations in dietary fiber intake could explain the difference. ${ }^{12}$ Diverticula were confirmed by plain films of the abdomen contrasted with oral barium. ${ }^{12}$ Nevertheless, the study was limited by selection bias and failure to account for confounding variables-vegetarians were in better health and younger then the non-vegetarians. ${ }^{12}$

Widespread use of colonoscopy now makes it possible to determine diverticulosis status and to study etiology in large populations. Two colonoscopy-based studies of diet and asymptomatic diverticulosis in Asian populations found no association. ${ }^{27,}{ }^{28}$ However, diverticulosis in Asians appears largely to be a different process than that seen in Western populations. Asians are more likely to have solitary congenital true diverticula in the cecum or acquired pseudo-diverticula in the ascending colon while Western populations have acquired pseudo-diverticula in the descending and sigmoid colon. ${ }^{24}$ Congenital true cecal diverticula are unlikely to have the same pathophysiology as acquired pseudo-diverticula. Whether pseudo-diverticula in the ascending colon and descending colon are the result of the same pathophysiology and have the same risk factors is unknown. In a previous study, we found that participants with regular bowel movements had a higher risk of diverticulosis compared to participants who had less frequent bowel movements and that dietary fiber intake was associated with a higher prevalence of diverticula. ${ }^{13}$ Unfortunately, that study may be open to response bias and reverse causality from the subjects' knowledge of their diagnoses. ${ }^{29}$

Some authors have speculated that diverticulosis might cause abdominal pain, which could lead subjects to increase fiber intake to obtain symptomatic relief. ${ }^{29}$ If so, abdominal pain could confound the relationship between dietary fiber intake and undiagnosed diverticulosis, especially if the pain improved with the dietary change. However, in the present study there was no association between dietary fiber intake and the presence of abdominal pain (14.8g versus $15.0 \mathrm{~g}, \mathrm{p}=0.69$ ). Furthermore, there was no difference in abdominal pain among our cases and controls ( $4 \%$ versus $5 \%, \mathrm{p}=0.08)$.

Rural African populations are reported to rarely have diverticula. ${ }^{30-33}$ To date, this finding has not been tied to race. However, we found that non-Caucasian participants had a $26 \%$ lower risk than Caucasians even after adjustment for risk factors. This raises the possibility that race is a risk factor independent of diet, smoking and other life style factors.

Obesity is associated with an increased risk of symptomatic diverticular disease. ${ }^{4}$ The relationship between obesity and asymptomatic diverticulosis is less clear. Our study found that subjects with an overweight or obese body mass index had an increased odds of diverticulosis compared to those with a normal body mass index. However, sedentary behavior and physical activity were not associated with an increased risk. In contrast, a series of sub-analyses within a large observational study of men found that sedentary behavior led to a $30 \%$ increased risk of asymptomatic diverticulosis but found no association with obesity and diverticulosis. ${ }^{3,4}$ Although cigarette smoking is thought to be associated with an increased risk of symptomatic diverticular disease, ${ }^{34,35}$ a relationship between tobacco use and asymptomatic diverticulosis has not been previously described. In our study, there was a increased odds of asymptomatic diverticulosis among cigarette smokers compared to those who never smoked. That contravenes the conventional thinking regarding the etiology of diverticula, as nicotine reduces colonic tone and muscular activity, and facilitates bowel movements. ${ }^{36}$

The present study, based on a secondary analysis of data collected for other purposes, has several potential weaknesses. The prevalence of diverticulosis increases with age, and the 
pathogenesis of diverticula may begin several decades before the disease manifests. Therefore, bowel habits and nutrition during a younger age may be more relevant than our data, which only covers the year prior to the colonoscopy. However, nutritional research has shown that diets do not change greatly over time and for many people recent diet is a reasonable reflection of diet several years or decades previously. ${ }^{37}$ Whether bowel habits change greatly over time is unknown.

As the initial, prospective collection of data was not focused on diverticulosis, it is possible that endoscopists may not have accurately recorded the presence of diverticula. Most (96\%) participants had diverticula recorded in an exact location. We interpreted this degree of detail to be an indicator of the high quality colonoscopy. Fortunately, our data also captured any prior diagnosis of diverticular disease, allowing us to assess the sensitivity of colonoscopy for diverticulosis. The exam detected almost all previously diagnosed cases (93\%) and therefore was sensitive in detecting diverticula.

Our dietary analyses were based on a structured quantitative food frequency questionnaire. Food frequency questionnaires are subject to measurement error, potentially leading to nondifferential misclassification and a conservative bias in the observed diet-diverticulosis association. The null effect of dietary fiber might be expected if there was only a limited range of dietary fiber intake in our population. However, in our analysis the mean total fiber intake in the highest quartile was 25 grams versus 8 grams in the lowest. This wide range makes it unlikely that homogeneity of intake accounts for the null association of fiber with the presence of diverticula.

In conclusion, our data challenge most current assumptions about the relationship between constipation, fiber intake and diverticulosis. Less frequent bowel movements and symptoms of constipation were not associated with an increased risk of diverticulosis in the descending or sigmoid colon. Dietary fiber intake was not associated with diverticulosis. Obesity and tobacco use are modifiable risk factors associated with an increased risk of asymptomatic diverticulosis in the descending or sigmoid colon although it is not yet clear if these associations are causal. Given the significant health burden of symptomatic diverticulitis, it is time to take a fresh look at risk factors and alternative hypotheses for asymptomatic diverticulosis.

\section{Acknowledgments}

Grant Support: This research was supported in part by grants from the National Institutes of Health T32 DK07634, P30 DK034987, R01 DK094738, R01 CA098286

\section{References}

1. Welch CE, Allen AW, Donaldson GA. An appraisal of resection of the colon for diverticulitis of the sigmoid. Ann Surg. 1953; 138(3):332-343. [PubMed: 13080959]

2. Peery AF, Dellon ES, Lund J, et al. Burden of Gastrointestinal Disease in the United States, 2012 Update. Gastroenterology. 2012; 143(5):1179-1187. [PubMed: 22885331]

3. Strate LL, Liu YL, Aldoori WH, et al. Physical activity decreases diverticular complications. Am J Gastroenterol. 2009; 104(5):1221-1230. [PubMed: 19367267]

4. Strate LL, Liu YL, Aldoori WH, et al. Obesity increases the risks of diverticulitis and diverticular bleeding. Gastroenterology. 2009; 136(1):115 e1-122 e1. [PubMed: 18996378]

5. Strate LL, Liu YL, Syngal S, et al. Nut, corn, and popcorn consumption and the incidence of diverticular disease. JAMA. 2008; 300(8):907-914. [PubMed: 18728264]

6. Rosemar A, Angeras U, Rosengren A. Body mass index and diverticular disease: a 28-year followup study in men. Dis Colon Rectum. 2008; 51(4):450-455. [PubMed: 18157570] 
7. Aldoori WH, Giovannucci EL, Rimm EB, et al. A prospective study of diet and the risk of symptomatic diverticular disease in men. Am J Clin Nutr. 1994; 60(5):757-764. [PubMed: 7942584]

8. Aldoori WH, Giovannucci EL, Rimm EB, et al. Prospective study of physical activity and the risk of symptomatic diverticular disease in men. Gut. 1995; 36(2):276-282. [PubMed: 7883230]

9. Aldoori WH, Giovannucci EL, Rimm EB, et al. A prospective study of alcohol, smoking, caffeine, and the risk of symptomatic diverticular disease in men. Ann Epidemiol. 1995; 5(3):221-228. [PubMed: 7606311]

10. Painter NS. The cause of diverticular disease of the colon, its symptoms and its complications. Review and hypothesis. J R Coll Surg Edinb. 1985; 30(2):118-122. [PubMed: 2991507]

11. Painter NS, Burkitt DP. Diverticular disease of the colon: a deficiency disease of Western civilization. Br Med J. 1971; 2(5759):450-454. [PubMed: 4930390]

12. Gear JS, Ware A, Fursdon P, et al. Symptomless diverticular disease and intake of dietary fibre. Lancet. 1979; 1(8115):511-514. [PubMed: 85104]

13. Peery AF, Barrett PR, Park D, et al. A high-fiber diet does not protect against asymptomatic diverticulosis. Gastroenterology. 2012; 142(2):266 e1-272 e1. [PubMed: 22062360]

14. Vandenbroucke JP, von Elm E, Altman DG, et al. Strengthening the Reporting of Observational Studies in Epidemiology (STROBE): explanation and elaboration. Ann Intern Med. 2007; 147(8):W163-W194. [PubMed: 17938389]

15. Block G, Hartman AM, Naughton D. A reduced dietary questionnaire: development and validation. Epidemiology. 1990; 1(1):58-64. [PubMed: 2081241]

16. Craig CL, Marshall AL, Sjostrom M, et al. International physical activity questionnaire: 12-country reliability and validity. Med Sci Sports Exerc. 2003; 35(8):1381-1395. [PubMed: 12900694]

17. Willett W, Stampfer MJ. Total energy intake: implications for epidemiologic analyses. Am J Epidemiol. 1986; 124(1):17-27. [PubMed: 3521261]

18. Painter NS. Diverticular disease of the colon--a disease of the century. Lancet. 1969; 2(7620):586588. [PubMed: 4186011]

19. Bassotti G, Battaglia E, Spinozzi F, et al. Twenty-four hour recordings of colonic motility in patients with diverticular disease: evidence for abnormal motility and propulsive activity. Dis Colon Rectum. 2001; 44(12):1814-1820. [PubMed: 11742167]

20. Painter NS, Truelove SC, Ardran GM, et al. Segmentation and the Localization of Intraluminal Pressures in the Human Colon, with Special Reference to the Pathogenesis of Colonic Diverticula. Gastroenterology. 1965; 49:169-177. [PubMed: 14323727]

21. Parks TG, Connell AM. Motility studies in diverticular disease of the colon. Gut. 1969; 10(7):534542. [PubMed: 5806933]

22. Weinreich J, Andersen D. Intraluminal pressure in the sigmoid colon. II. Patients with sigmoid diverticula and related conditions. Scand J Gastroenterol. 1976; 11(6):581-586. [PubMed: 981962]

23. Weinreich J, Moller SH, Andersen D. Colonic haustral pattern in relation to pressure activity and presence of diverticula. Scand J Gastroenterol. 1977; 12(7):857-864. [PubMed: 594654]

24. Leandro PA, Cecconello I, Habr-Gama A, et al. Gastrointestinal motility in normal subjects and patients with diverticulosis of the colon. Arq Gastroenterol. 1984; 21(4):157-163. [PubMed: 6536253]

25. Viebig RG, Pontes JF, Michelsohn NH. Electromanometry of the rectosigmoid in colonic diverticulosis. Arq Gastroenterol. 1994; 31(4):135-144. [PubMed: 7575173]

26. Bassotti G, Villanacci V. Colonic diverticular disease: abnormalities of neuromuscular function. Dig Dis. 2012; 30(1):24-28. [PubMed: 22572681]

27. Song JH, Kim YS, Lee JH, et al. Clinical characteristics of colonic diverticulosis in Korea: a prospective study. Korean J Intern Med. 2010; 25(2):140-146. [PubMed: 20526386]

28. Lin OS, Soon MS, Wu SS, et al. Dietary habits and right-sided colonic diverticulosis. Dis Colon Rectum. 2000; 43(10):1412-1418. [PubMed: 11052519]

29. Strate LL. Diverticulosis and dietary fiber: rethinking the relationship. Gastroenterology. 2012; 142(2):205-207. [PubMed: 22185897] 
30. Elbatea H, Enaba M, Elkassas G, et al. Indications and outcome of colonoscopy in the middle of Nile delta of Egypt. Dig Dis Sci. 2011; 56(7):2120-2123. [PubMed: 21221792]

31. Ogunbiyi OA. Diverticular disease of the colon in Ibadan, Nigeria. Afr J Med Med Sci. 1989; 18(4):241-244. [PubMed: 2558553]

32. Ogutu EO, Okoth FA, Lule GN. Colonoscopic findings in Kenyan African patients. East Afr Med J. 1998; 75(9):540-543. [PubMed: 10493058]

33. Segal I, Walker AR. Diverticular disease in urban Africans in South Africa. Digestion. 1982; 24(1):42-46. [PubMed: 6813167]

34. Turunen P, Wikstrom H, Carpelan-Holmstrom M, et al. Smoking increases the incidence of complicated diverticular disease of the sigmoid colon. Scand J Surg. 2010; 99(1):14-17. [PubMed: 20501352]

35. Hjern F, Wolk A, Hakansson N. Smoking and the risk of diverticular disease in women. Br J Surg. 2011; 98(7):997-1002. [PubMed: 21462366]

36. Thomas GA, Rhodes J, Ingram JR. Mechanisms of disease: nicotine--a review of its actions in the context of gastrointestinal disease. Nat Clin Pract Gastroenterol Hepatol. 2005; 2(11):536-544. [PubMed: 16355159]

37. Dunn JE, Liu K, Greenland P, et al. Seven-year tracking of dietary factors in young adults: the CARDIA study. Am J Prev Med. 2000; 18(1):38-45. [PubMed: 10808981] 
Table 1

Population Characteristics

\begin{tabular}{|c|c|c|c|}
\hline & No diverticulosis & Diverticulosis & \\
\hline & $n=1569$ & $n=539$ & p-value \\
\hline & \multicolumn{3}{|c|}{ Mean \pm standard deviation or $n(\%)$} \\
\hline Age, years & $56.6 \pm 6.5$ & $59.9 \pm 6.7$ & $<0.0001$ \\
\hline Male & $942(60)$ & $374(69)$ & 0.0001 \\
\hline Caucasian & $1234(84)$ & $454(88)$ & 0.03 \\
\hline Education, years & $11.4 \pm 2.9$ & $11.5 \pm 2.8$ & 0.3 \\
\hline $\mathrm{BMI}, \mathrm{kg} / \mathrm{m}^{2}$ & $28.7 \pm 5.3$ & $29.5 \pm 4.9$ & 0.001 \\
\hline NSAID use ( $\geq 1$ day/week) & $353(23)$ & $125(23)$ & 0.8 \\
\hline ASA use ( $\geq 1$ day/week) & $587(37)$ & $234(43)$ & 0.01 \\
\hline History of cigarette smoking & & & 0.007 \\
\hline Never & $886(55)$ & $256(48)$ & \\
\hline Former & $545(35)$ & $224(42)$ & \\
\hline Current & $158(10)$ & $59(11)$ & \\
\hline Alcohol use, drinks/day & $0.69 \pm 1.0$ & $0.81 \pm 1.1$ & 0.03 \\
\hline Total energy intake, $\mathrm{kcal} / \mathrm{day}$ & $1580 \pm 598$ & $1590 \pm 582$ & 0.7 \\
\hline Total fiber, grams/day & $15.3 \pm 7.1$ & $14.8 \pm 6.5$ & 0.2 \\
\hline Bean Fiber, grams/day & $2.2 \pm 2.2$ & $2.1 \pm 1.9$ & 0.4 \\
\hline Grain Fiber, grams/day & $6.2 \pm 3.5$ & $6.0 \pm 3.4$ & 0.4 \\
\hline Fruit \& Vegetable Fiber, grams/day & $7.2 \pm 4.3$ & $6.9 \pm 3.8$ & 0.2 \\
\hline Supplemental fiber & $74(5)$ & $28(5)$ & 0.7 \\
\hline Red meat, servings/day & $0.68 \pm 0.67$ & $0.68 \pm 0.67$ & 0.9 \\
\hline Fat, g/day & $66.0 \pm 29.8$ & $67.4 \pm 29.1$ & 0.4 \\
\hline Physical activity, METS-min/week & $4220 \pm 4003$ & $4333 \pm 4031$ & 0.6 \\
\hline Sedentary behavior, minutes sitting on weekday & $393 \pm 199$ & $382 \pm 191$ & 0.3 \\
\hline Bowel movements per week & $8.7 \pm 4.8$ & $9.6 \pm 4.9$ & 0.0003 \\
\hline Strain with bowel movement, $\geq 25 \%$ time & $159(10)$ & $46(9)$ & 0.3 \\
\hline Incomplete bowel empty feeling, $\geq 25 \%$ time & $179(11)$ & $51(10)$ & 0.2 \\
\hline Hard or lumpy stool, $\geq 25 \%$ time & $239(15)$ & $60(11)$ & 0.02 \\
\hline Abdominal pain & $67(4)$ & $14(3)$ & 0.08 \\
\hline Laxative use/last year & $114(7)$ & $38(7)$ & 0.9 \\
\hline Number of colorectal exams in a lifetime & $1.8 \pm 1.1$ & $2.0 \pm 1.8$ & 0.001 \\
\hline
\end{tabular}


Table 2

Association of Symptoms of Constipation and Abdominal Pain with Diverticulosis

\begin{tabular}{|c|c|c|}
\hline & $\mathbf{n}$ & OR $(95 \% \mathrm{CI})^{I}$ \\
\hline \multicolumn{3}{|l|}{ Strain during bowel movement } \\
\hline Less than $25 \%$ of the time & 1894 & 1 \\
\hline $25 \%$ or more of the time & 205 & $0.85(0.59,1.22)$ \\
\hline \multicolumn{3}{|c|}{ Feeling of incomplete bowel movement } \\
\hline Less than $25 \%$ of the time & 1868 & 1 \\
\hline $25 \%$ or more of the time & 230 & $0.85(0.61,1.20)$ \\
\hline \multicolumn{3}{|l|}{ Hard or lumpy stool } \\
\hline Less than $25 \%$ of the time & 1794 & 1 \\
\hline $25 \%$ or more of the time & 299 & $0.75(0.55,1.02)$ \\
\hline \multicolumn{3}{|c|}{ Some or severe abdominal pain in the last year } \\
\hline None & 2027 & 1 \\
\hline Some or severe & 81 & $0.77(0.42,1.40)$ \\
\hline
\end{tabular}


Table 4

Assessment of Risk Factors for Diverticulosis

\begin{tabular}{|c|c|c|}
\hline & $\mathbf{n}$ & OR $(95 \% \mathrm{CI})^{I}$ \\
\hline \multicolumn{3}{|l|}{ NSAID Use } \\
\hline Never / Non-Regular User & 1,628 & 1 \\
\hline Regular user & 478 & $1.14(0.90,1.45)$ \\
\hline \multicolumn{3}{|l|}{ ASA Use } \\
\hline Never / Non-Regular User & 1,287 & 1 \\
\hline Regular user & 821 & $0.99(0.80,1.23)$ \\
\hline \multicolumn{3}{|l|}{ Race } \\
\hline Caucasian & 1,688 & 1 \\
\hline Not Caucasian & 304 & $0.74(0.55,1.00)$ \\
\hline \multicolumn{3}{|l|}{ BMI } \\
\hline Normal & 495 & 1 \\
\hline Overweight or Obese & 1,608 & $1.65(1.27,2.15)$ \\
\hline \multicolumn{3}{|l|}{ Cigarette smoking } \\
\hline Never & 1,122 & 1 \\
\hline Former & 769 & $1.24(1.01,1.52)$ \\
\hline \multicolumn{3}{|l|}{ Cigarette smoking } \\
\hline Never & 1,122 & 1 \\
\hline Current & 217 & $1.42(1.01,2.00)$ \\
\hline
\end{tabular}

${ }^{1}$ Adjusted for sex and age 